\title{
Experimental Research on Mechanical Characteristics of CRTSIII Slab Ballastless Track under Train Load
}

\author{
Zeng Zhiping ${ }^{1,2, a}$, He Xianfeng ${ }^{1, b}$, Luo Jun ${ }^{1, c}$ and Meng Xiaobai ${ }^{1, d}$ \\ ${ }^{1}$ School of Civil Engineering, Central South University, Changsha 410075, China \\ ${ }^{2}$ National Engineering Laboratory for High-Speed Railway Construction, Changsha 410075, China \\ a61134963@qq.com, b1239435840@qq.com, c1964965318@qq.com, d2277318169@qq.com
}

Keywords: CRTSIII slab ballastless track; self-compacting concrete thickness; fatigue experiment; mechanical characteristicsics

Abstract. This paper studied on the fatigue experiment of two CRTSIII slab ballastless tracks on subgrade under high-speed train load, one was the track structure with self-compacting concrete thickness of $70 \mathrm{~mm}$ (the 70's), the other was $90 \mathrm{~mm}$ (the $90 \mathrm{~s}$ ). The two tracks were made of 1:1 full-scale test models and were carried out 3million times fatigue load test respectively. The experimental results show that the self-compacting concrete thickness greatly affects the track structural stress. Based on track structures with different self-compacting concrete thickness, self-compacting concrete and base concrete stress were analyzed comparatively. The research results provide guiding significance for the practical production.

\section{Introduction}

As a new type of ballastless track, CRTSIII slab structure was developed based on optimization and innovation of CRTSI and CRTSII, and China owns its intellectual property rights. The mechanical characteristics of CRTSIII slab ballastless track have brought widespread concern of scholars. Hanmin WANG[1] analyzed the change of mechanical characteristics of track panel and base panel in response to the structure parameters by establishing finite element model of CRTSIII slab ballastless track on subgrade. Lu SUN[2] et al. analyzed static characteristics of the structure by using high-speed railway CRTSIII slab ballastless track. China Academy of Railway Sciences[3] et al. systemly studied on the key parameters and static and dynamic characteristics of the reasonable scale of many parts, fasteners reasonable stiffness, reasonable Stiffness isolation layer, function positioning of CRTSIII slab ballastless track, by establishing static structural finite element model and vehicle-track-basic coupled dynamic model. Self-compacting concrete thickness is one of the key mechanical parameters of CRTSIII slab ballastless track, this paper studied on the influence regular pattern of track mechanical characteristicsics in response to the self-compacting concrete thickness.

\section{Experimental Program}

Experiments of 1:1 full-scale test models of two ballastless tracks with different self-compacting concrete thickness $(90 \mathrm{~mm}$ and $70 \mathrm{~mm}$ ) were carried out, and 3 million times fatigue test was carried out respectively.

CRTSIII Slab Track Test Model Imitating on Subgrade. Subgrade supporting role was played by rubber pad, with the size of $6060 \mathrm{~mm} \times 3330 \mathrm{~mm} \times 76 \mathrm{~mm}$. In addition to the track panels, the base panels, self-compacting concrete etc. were made strictly according to the relevant design drawings, using materials and construction technology consistent with the construction site and by the professional team in the laboratory, as is shown in Fig. 1. 


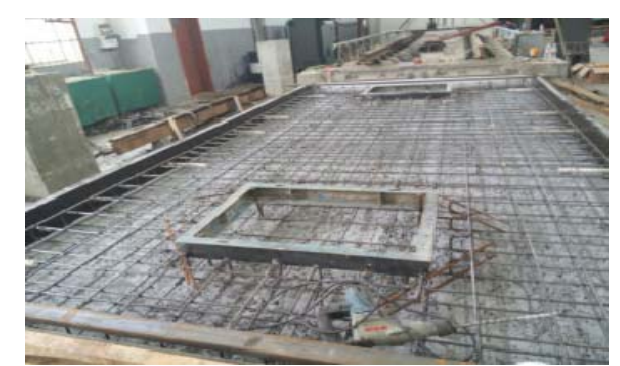

(a) Construction of steel mesh inside base

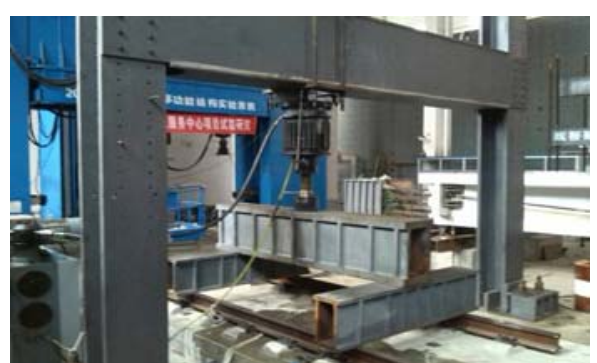

(b) Test loading device

Fig. 1 The test model of CRTSIII slab ballastless track structure on simulated subgrade

Test Content and Component Arranging. The specific test contents include: the strain of self-compacting concrete and base concrete. Strain gauges were arranged, as is shown in Fig. 2 . As is shown in Fig. 2(b), Q, F, H, S, L, T represents portrait quarter, longitudinal load point, longitudinal middle of the panel, lateral middle of the panel and lateral panel edge, for exemple, H-S-L represents the strain of longitudinal middle of the panel and lateral panel edge.

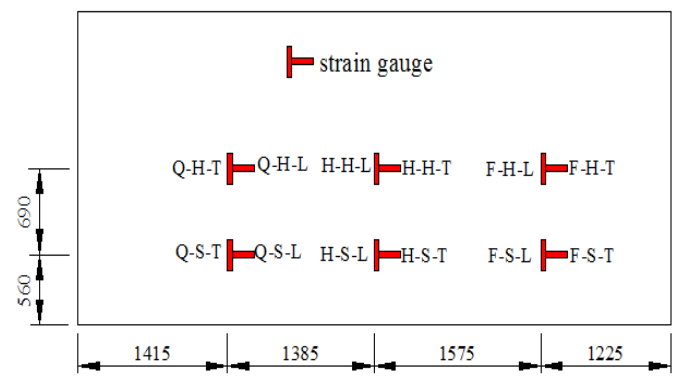

(a) Strain guage of the track structure

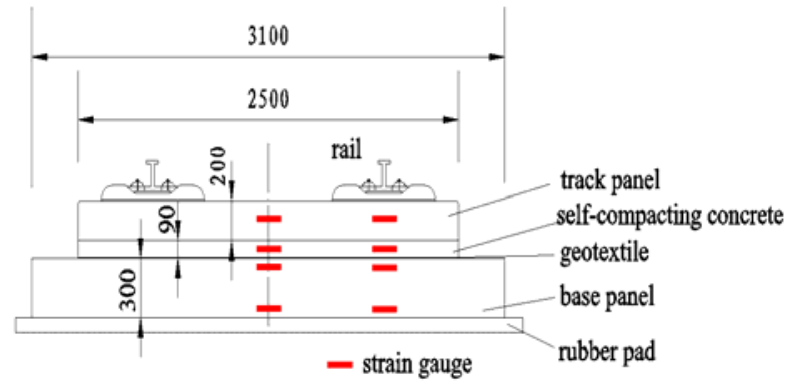

(b) Cross section of the track structure

Fig. 2 The layout of test element

Load Program. The experiments were carried out by PMW-1200 pulsating electro-hydraulic fatigue testing machine with loading frequency of $2 \sim 8 \mathrm{~Hz}$ in National Engineering Laboratory for High Speed Railway. The wheel was simulated by distribution beam, when the load acts, that was equivalent to the wheel acting, as is shown in Fig. 3. Simplified calculation method was used in dynamic load test simulation, high-speed train's maximum axle load is $17 \mathrm{t}$, considering the power factor 2.5 times, the maximum fatigue load was $850 \mathrm{KN}$, its minimum was $85 \mathrm{KN}$. In order to study the effects of fatigue track structure, static load test was carried out during the whole process, respectively, before the dynamic load test, after 250000, 500000, 1000000, 1500000, 2000000, 2500, 000 and 3000000 times the static load rating load test was carried out. The static load rating load was carried out by $0,50,100$, $150,200,300,350$ and $400 \mathrm{KN}$, respectively measuring the strain of every level. Figure 4 shows the load curve .

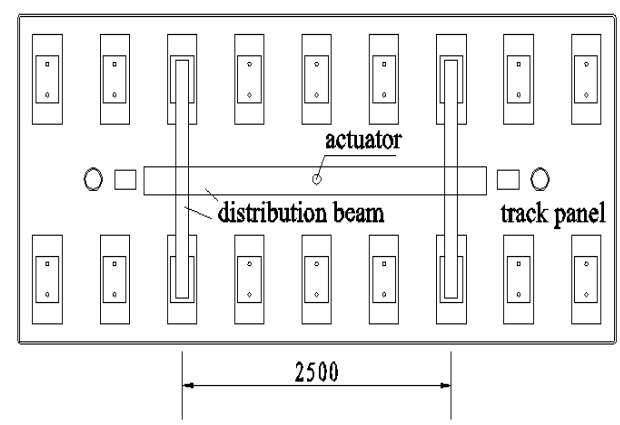

(a)Loading way

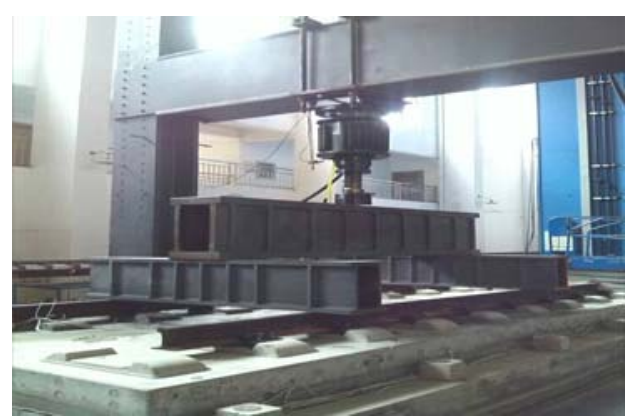

(b) The arranging way of beam

Fig. 3 Ballastless track model test system 


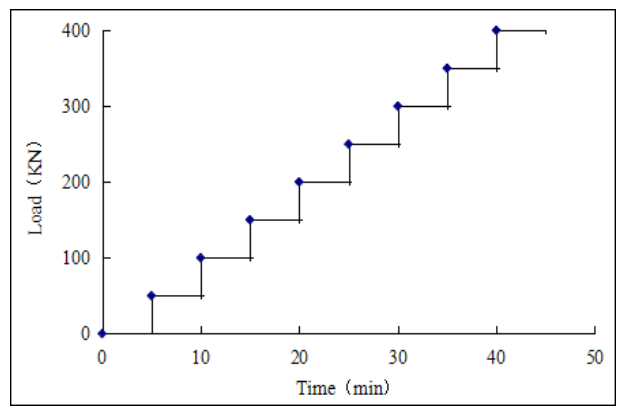

(a) Static load curve

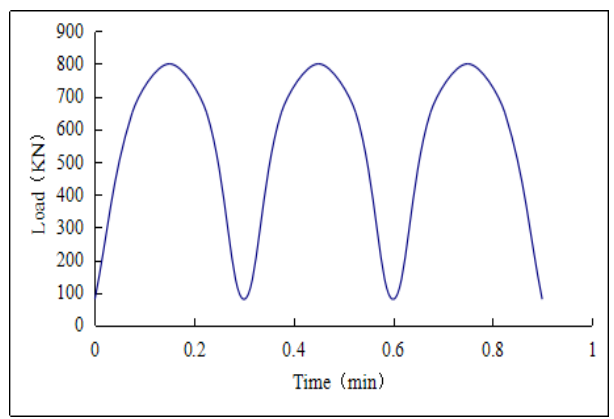

(b) Dynamic load curve

Fig. 4 Test load curve

\section{Analysis of the Results}

3million fatigue load test was respectively carried out on the two CRTSIII slab ballastless tracks with different self-compacting concrete thickness $(90 \mathrm{~mm}$ and $70 \mathrm{~mm})$. Various representative locations of cross-section was selected for comparative analysis.

As is shown in Table 1, positive values indicate tensile strain, negative values indicate compressive strain. The 90's self-compacting concrete H-H-T strain is compressive, the others are tensile. With the increase of test times the maximum of self-compacting concrete strain declines, and after every one million times, strain decreases $1 \mu \varepsilon$. After 3 million times, the strain decreases $10 \%-25 \%$. Self-compacting concrete strain of the panel edge position is about two times that of the middle. The H-S-L strain is the maximum. For the 70's, except that the H-H-T strain is compressive, the others are sensile. Self-compacting concrete strain of the panel edge position is about two times that of the middle. With the increase of test times the maximum of self-compacting concrete strain declines. After every one million times, the strain decreases $1 \mu \varepsilon$. After 3 million times, H-H-T, H-H-L, H-S-T, H-S-L strain reduces $12.5 \%, 9.1 \%, 8 \%$ and $6.3 \%$ respectively. With the increase of test times the maximum of self-compacting concrete strain of the two tracks declines, after 3 million times, the reduced amplitude of each strain is within $10 \%-20 \%$. With the same test times and same position, the maximum of self-compacting concrete strain of the $70 \mathrm{~mm}$ 's is $1.2-1.5$ times that of the $90 \mathrm{~mm}$ 's.

Table 1 Self-compacting concrete $\operatorname{strain}(\mu \varepsilon)$

\begin{tabular}{cccccc}
\hline $\begin{array}{c}\text { Number of times } \\
(\text { million })\end{array}$ & $\begin{array}{c}\text { Self-compacting concrete } \\
\text { thickness }(\mathrm{mm})\end{array}$ & H-H-T & H-H-L & H-S-T & H-S-L \\
\hline \multirow{2}{*}{0} & 90 & -6 & 8 & 10 & 14 \\
& 70 & -8 & 11 & 12 & 17 \\
50 & 90 & -6 & 8 & 10 & 14 \\
& 70 & -8 & 10 & 12 & 17 \\
100 & 90 & -6 & 8 & 10 & 14 \\
& 70 & -8 & 10 & 12 & 16 \\
150 & 90 & -6 & 7 & 9 & 13 \\
& 70 & -8 & 10 & 12 & 16 \\
200 & 90 & -5 & 7 & 9 & 13 \\
& 70 & -7 & 9 & 12 & 16 \\
250 & 90 & -5 & 6 & 8 & 12 \\
& 70 & -7 & 9 & 11 & 16 \\
& 90 & -5 & 6 & 8 & 12 \\
& 90 & -7 & 9 & 11 & 15 \\
\hline
\end{tabular}

As is shown in Table 2, the data format is: upper concrete strain / lower concrete strain, and positive values indicate tensile strain, negative values indicate compressive strain. The 90's upper 
base concrete strain is the maximum and that is compressive. The maximum tensile strain is that of the lower H-H-L. With the increase of test times the maximum of the strain of the base concrete increases. After 3 million times, each strain increases $1-2 \mu \varepsilon$. The base concrete strain of the longitudinal position is tensile. The upper H-H-T strain is the maximum. With the increase of test times the maximum of the strain of the base concrete increases. After 3million times, each strain increases $1-3 \mu \varepsilon$. Both of the two tracks' base concrete strain increase as the test times increase. After 3 million times, the maximum of the base concrete strain of the 90's and 70's increases $12.5 \%$ and $20.0 \%$ respectively. With the same test times and same position, the maximum of base concrete strain of the $70 \mathrm{~mm}$ 's is $1.2-1.4$ times that of the $90 \mathrm{~mm}$ 's.

Table 2 Base concrete strain $(\mu \varepsilon)$

\begin{tabular}{cccccc}
\hline $\begin{array}{c}\text { Number of times } \\
(\text { million })\end{array}$ & $\begin{array}{c}\text { Self-compacting concrete } \\
\text { thickness }(\mathrm{mm})\end{array}$ & H-H-T & H-H-L & H-S-T & H-S-L \\
\hline \multirow{2}{*}{0} & 90 & $-8 / 2$ & $1 / 3$ & $-3 / 3$ & $2 / 3$ \\
& 70 & $-10 / 3$ & $1 / 4$ & $-3 / 4$ & $3 / 4$ \\
50 & 90 & $-8 / 2$ & $1 / 3$ & $-3 / 3$ & $2 / 3$ \\
& 70 & $-10 / 3$ & $1 / 4$ & $-3 / 4$ & $3 / 4$ \\
100 & 90 & $-8 / 2$ & $1 / 3$ & $-3 / 3$ & $2 / 4$ \\
& 70 & $-10 / 3$ & $1 / 4$ & $-3 / 4$ & $3 / 4$ \\
\multirow{2}{*}{150} & 90 & $-8 / 2$ & $2 / 4$ & $-3 / 3$ & $2 / 4$ \\
& 70 & $-10 / 3$ & $2 / 4$ & $-3 / 4$ & $3 / 4$ \\
\multirow{2}{*}{200} & 90 & $-9 / 2$ & $2 / 4$ & $-3 / 3$ & $2 / 4$ \\
& 70 & $-11 / 4$ & $2 / 5$ & $-3 / 4$ & $4 / 5$ \\
& 90 & $-9 / 3$ & $2 / 4$ & $-3 / 4$ & $3 / 5$ \\
& 90 & $-11 / 4$ & $2 / 5$ & $-4 / 5$ & $4 / 5$ \\
& 70 & $-9 / 3$ & $2 / 5$ & $-3 / 4$ & $3 / 5$ \\
& 90 & $-12 / 4$ & $2 / 5$ & $-4 / 5$ & $5 / 6$ \\
\hline
\end{tabular}

\section{Conclusions}

1. The maximum of self-compacting concrete stress occurs in the H-S-L. The maximum of base concrete stress occurs in the upper H-H-T. The self-compacting concrete strain of the panel edge is about 2 times that of the middle. Structural design should reinforce the structural strength and durability of the weaknesses.

2. With the test times increase, the self-compacting concrete stress of the two tracks declines, and after 3million times, the reduced amplitude of each strain are within $10 \%-20 \%$. With the same test times and same position, the maximum of self-compacting concrete strain of the $70 \mathrm{~mm}$ 's is $1.2-1.5$ times that of the $90 \mathrm{~mm}$ 's. With the increase of test times, the maximum of the base concrete stress increases. After 3million times, the maximum of base concrete strain of the 90's and the 70's increases $12.5 \%$ and $20 \%$ respectively. With the same test times and same position, the maximum of base concrete strain of the $70 \mathrm{~mm}$ 's is 1.2-1.4 times that of the $90 \mathrm{~mm}$ 's. We can see that the self-compacting concrete thickness greatly affects the track structure stress, which provides reference value for the track structure design.

\section{Acknowledgements}

The research described in this paper was financially supported by the Project of Innovation-driven Plan in Central South University and the Program for Changjiang Scholars and Innovative Research Team in University (Grant No. IRT1296). 


\section{References}

[1] WANG Hanmin. Reaserch on Mechanical Characteristics of CRTSIII Slab Ballastless Track on Subgrade [J]. Shanxi Architecture, 2014, 40(30): 158-159. (In Chinese)

[2] SUN Lu, DUAN Yufen, YANG Xin. Static Response Analysis of CRTS III Type Slab Ballastless Track [J]. Journal of Railway Engineering Society, 2013, 16(11): 32-39. (In Chinese)

[3] China Academy of Railway Sciences, Southwest Jiaotong University, Beijing Jiaotong University. Theory and Further Study on the Main Parts of CRTS III Type Slab Ballastless Track [R]. Beijing: China Academy of Railway Sciences, 2014. (In Chinese)

[4] TIAN Qiyi, WANG Junwen, SHI Yan, ZHANG Xiangdong. Experimental Research on Mechanical Characteristics of CRTSII Slab Ballastless Track Panels [J]. Journal of Shijiazhuang Tiedao University(Natural Science Edition), 2010, 23(4): 36-40. (In Chinese)

[5] WANG Anhua. Reaserch on of CRTSIII Slab Ballastless Track [D]. Beijing:Beijing Jiaotong University, $2012: 1-10$. (In Chinese)

[6] HE Yanping. Study on Fatigue Property of CRTS III Type Slab Ballastless Track [D]. Chengdu: Southwest Jiaotong University, 2011. (In Chinese)

[7] ZHAO Guotang. Ballastless Track of High-Speed Railway[M]. Beijing:China Raiway Press, 2011:2-34. (In Chinese)

[8] GU Haipeng. Research on Filling Layer Self-compacting Concrete of CRTSIII Track [D].

Chengdu:Southwest Jiaotong University, 2013.(In Chinese)

[9] WANG Chengxiao. Research on the Mechanical Characteristics of CRTSIII Slab Ballastless Track [D]. Beijing:Beijing Jiaotong University, 2011. (In Chinese)

[10] ZHAI Wanming, CAI Chengbiao et al. Research on the Dynamic Characteristics of High-speed rail Slab Track [J]. Journal of the China Railway Society, 1999, 21(6):65-69. (In Chinese) 